\section{A QCD Outlook}

\author{
H. David Politzer* \\ California Institute of Technology, Pasadena, California 91125, U.S.A.
}

Received August 1, 1980; accepted September 9, 1980

My charge from the organizers of this QCD Symposium was to present a summary of what I regard to be the successes and the disappointments we have had with QCD. And furthermore, I was asked to discern the crucial issues and tests that lie ahead. So I have spent many hours gazing into my crystal ball. Consequently, rather than the typical conference summary, this discussion is far more metaphysics than physics.

As evidence that something peculiar (or at least very interesting) has transpired, I offer a list of the major advances in high energy theory of the past decade. For emphasis, I divide the decade in half. In the years 1974 and before we saw:

- Scaling and the parton model (this started in the 60's but spilled over significantly into the 70's);

- the re-invention of gauge theories by 't Hooft (probably the most significant advance of the era);

- neutral currents and the Weinberg-Salam model (the latter was not noticed by anyone, including its creators, until 1971);

- QCD - prediction of scaling violations; explanation of the origin of flavor symmetries, current algebra, and strong $C, P$ and $T$; qualitative features of the spectrum from color confinement and splittings from short-range, onegluon exchange spin forces.

- GUTS - SU(5) prediction of $\theta_{w}$ and proton decay. (This required the experimental re-confirmation of $\mathrm{SU}(2) \times$ $\mathrm{U}(1)$ before becoming popular.)

- heavy quarks $-R_{e^{+} e^{-}}$and onium spectroscopy (QCD helped us survive the naidir of quark physics, when Burt Richter observed the electron to be a little hadron);

- approaches to non-perturbative QCD: lattices, bags, strings, vortices, $1 / N$.

Since then, in the year 1975 and after, our collective output pales in comparison:

- solution of the $\mathrm{U}(1)-\eta$ puzzle (but we paid the price of losing our understanding of strong $\mathrm{CP}$ );

- QCD predictions of jets, hadronic inclusive and exclusive cross sections;

- supersymmetry and supergravity (ideas before their time);

- evidence (?) for the absence of a non-confining phase transition in non-Abelian gauge theories;

- loss of our non-perturbative naiveté.

I do not think that we have become stupider, but it is certainly true that the nature of the progress has become qualitatively different. If one wanted to be generous, one could describe our field as "maturing".

The greatest succes of QCD is that it made quarks respectable. It provided qualitative answers to hitherto paradoxical features of quarks (e.g., statistics, scaling versus confinement)

\footnotetext{
* Work supported in part by the U.S. Department of Energy under Contract No. DE-AC-03-79ER0068, and by the Alfred P. Sloan Foundation.
}

and offered a prospect of a detailed dynamical theory. The second "greatest success" is that perturbative QCD works experimentally within (or better than) theoretical expectations.

It is a subjective issue as to what constitutes a disappointment. To me, the lack of precision in the short-distance predictions is most frustrating. Secondly, even though we have explicit equations of motion, we have no clear picture or qualitative description of the bound states. (At least, most of us do not understand confinement; those lucky few who do don't agree with each other.) And finally, the lack of a theory even of onium spectroscopy following from first principles is a personal disappointment. (Perhaps, though, lattice caculations may soon be used as an a posteriori justification of the potential models that have been used successfully.)

\section{ilo Principiorum Philosophif.}

puncto A exiftens, moveretur etiam verfùs $C$, fi linea EY effet baculus, fupra quem rectà incederet ab A

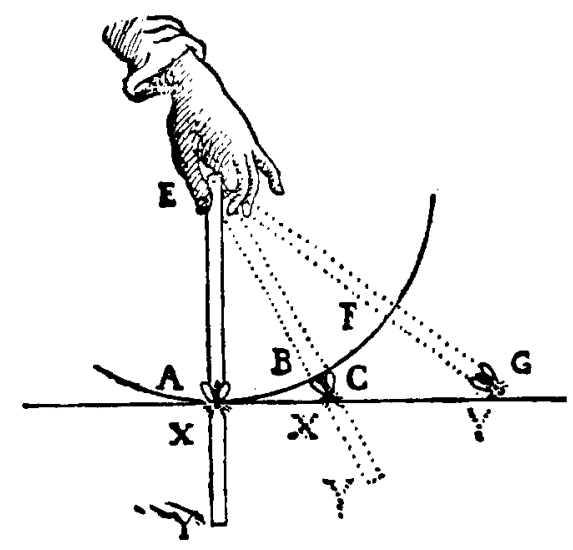

verius $Y$, dum interim ipfe baculus verteretur circa centrum $\mathrm{E}$, ac ejufdem baculi punctum $\mathrm{A}$ defcriberet

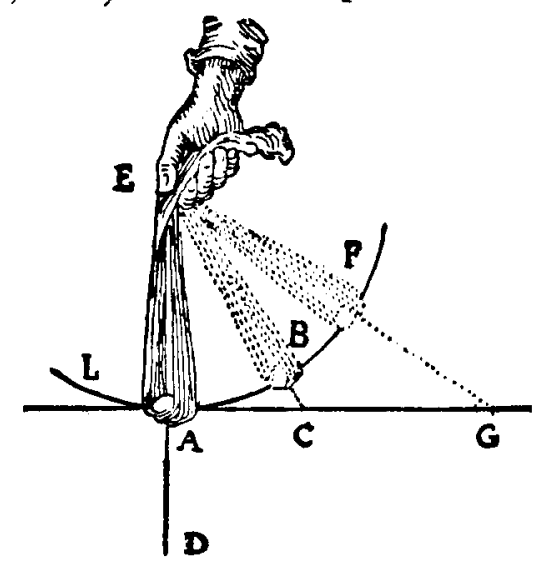

circulum $A B F$, effentque hi duo motus ita inter fe contemperati, ut formica perveniret ad $X$ cùm bacu-

Fig. 1 


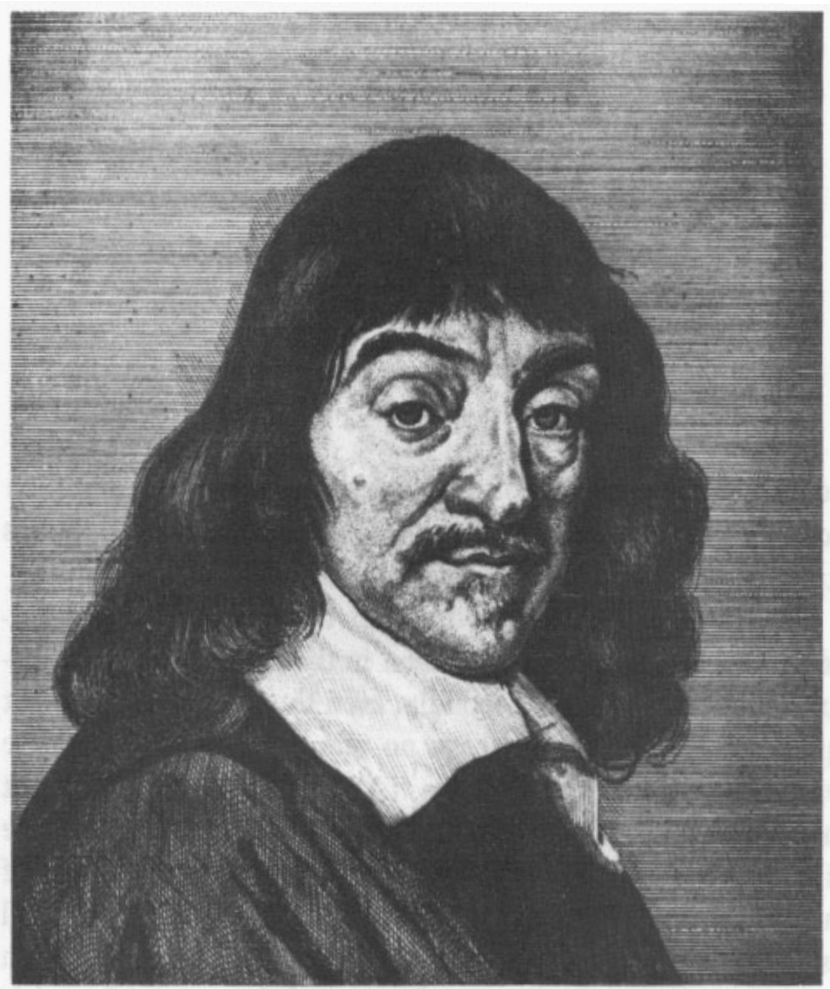

Fig. 2

Nevertheless, we (virtually) all believe in QCD. Is this simply mass hysteria? After all, we have seen no experimentum cruxis, no test, no high precision prediction, and we can add little to the qualitative arguments offered in 1973-4 for QCD except perhaps jets, growing $p_{\perp}$ phenomena as in $\mu$-pair production, and the $\mathrm{U}(1)-\eta$ resolution. One of my colleagues, George Zweig, (with what may admittedly be a vested interest in quarks) does find the orthodoxy rather non-compelling. He has spent the past year investigating the chemical properties of fractionally-charged ions. He argues effectively that the null results from quark searches in bulk matter should all be regarded as totally inconclusive.

But I am in fact impressed by the experimental success of QCD. We did predict new phenomena, which were subsequently observed. The main reason we are still uncomfortable with QCD is that there is a whole realm of important physics that we don't even qualitatively understand.

I would like to digress on what constitutes scientific understanding by going back to a great debate of the 17 th Century. The debate concerned the motion of the planets. It was known how they moved (i.e., in elipses), but why did they move thus? Could we understand their motion?

Descartes lead one school of thought. It is clear from the Figure I have reproduced from his Principiorum Philosophiae (Fig. 1) that he understood the need of a centripital force to produce circular (or a curvilinear) motion. His concern, though, was the origin and nature of that force. (From a brief perusal of just his scientific writings, it is clear he was a genius of the highest order. I like to think that this portrait, Fig. 2, conveys, in addition to his intellect, an element of Gallic wit and élan.) He did not accept action at a distance, which is to say long range correlations in the vacuum. Rather, he insisted that all accelerated motion must be the result of the motion of a local, non-trivial flow field. Descartes' picture (Fig. 3) shows a striking resemblance to pictures of the $\mathrm{QCD}$ vacuum. A minor
136

\section{Principiorum Philosophie}

experimentum capi poffit : nempe, cùm fortè aliquis Cometa tantam cœli partem pererrat, ut primò vifus

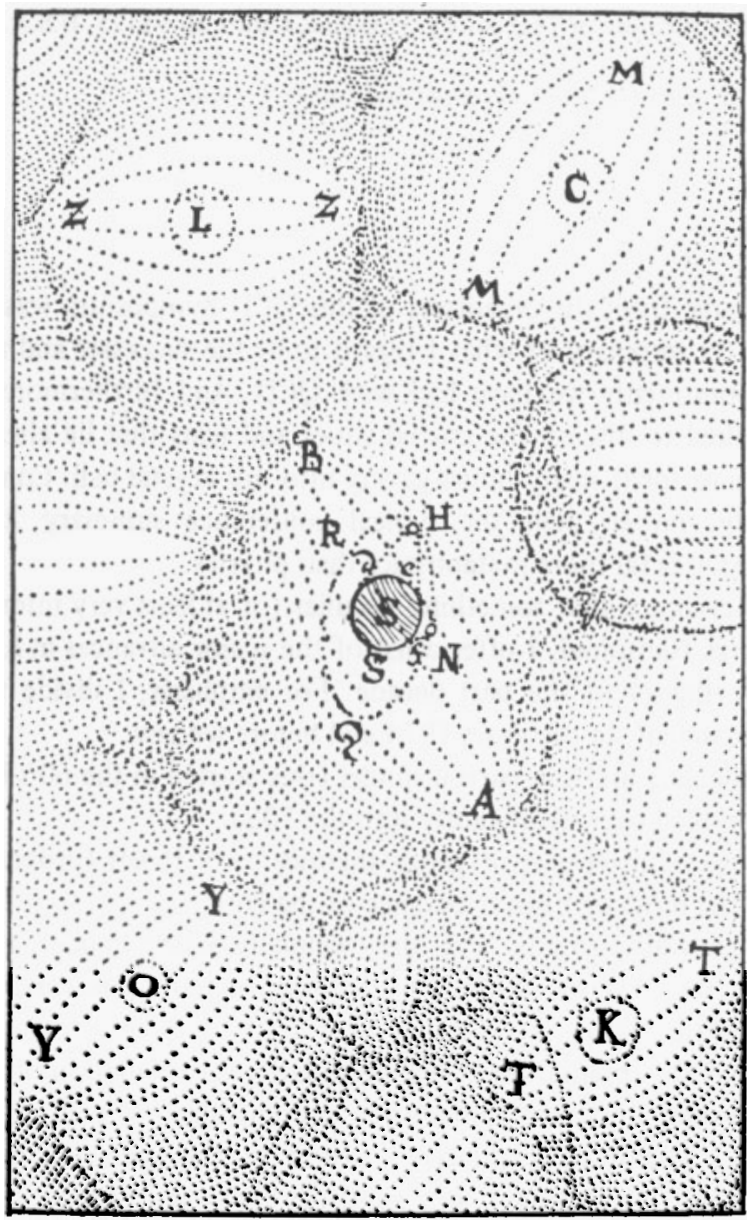

in eclipticâ, videatur deinde verfus unum ex polis, ac poftea rurfus in eclipticâ; tunc enim habitâ ratione Fig. 3

difference is that Descartes thought the regions of correlated, non-trivial background field were lightyears in diameter. In any case, it was these flows or vortices that carried planets around stars.

In attacking this picture, Newton raised the issue of the motion of comets, whose orbits where enormous, but still simple and often eliptical. But were comets an inessential detail? A different phenomenon? No, insisted Newton.

Descartes knew that comets were a problem but was able to understand their motion qualitatively (the path RQDC in Fig. 4. from Traité de la Lumière) by drawing on analogies with solid state or many-body physics. [See Fig. 5.]

Newton confessed he did non "understand" the origin of gravity. Such understanding was intimately tied up with the will of the Almighty. Religous issues were important to Newton, but he had a clear distinction in mind between scientific and non-scientific thinking. He insisted that there is no room in science for hypotheses that are untestable or have no consequences beyond themselves. As exemplar of this point of view, Newton has come down to us as a hero of modern physics. (See Fig. 6 for a picture of Newton exuding Anglo-Saxon virtues.) Just a sample illustration from his Principia (Fig. 7) gives a sense of the precision and virtues of this approach. 
Traité de la lumiere.

Element, on peut penfer qu'elle eft égale en toutes celles qui font depuis la circonference exterieure du

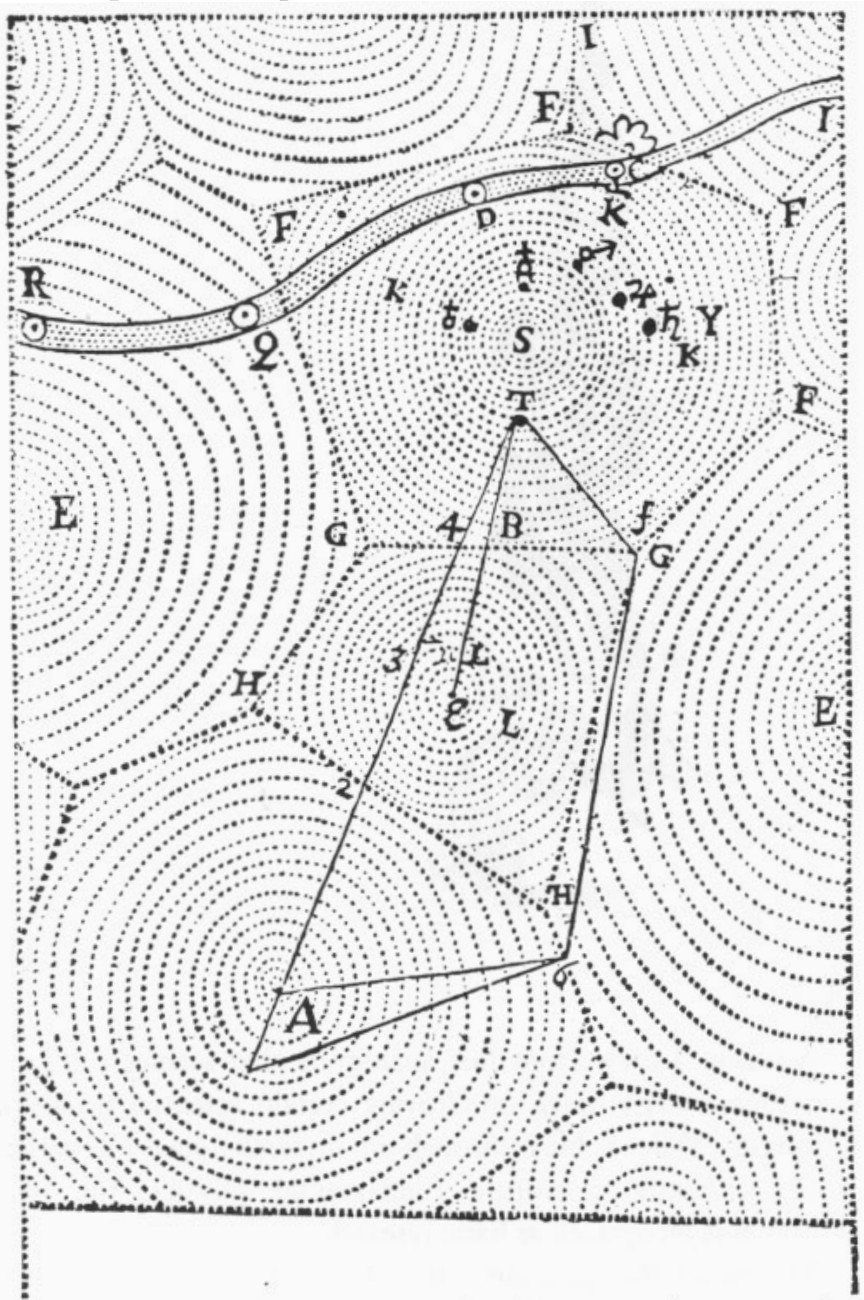

Ciel FGGF, jufques au cercle KK; ou mefmes, que les

$3 \mathrm{KK}] \mathrm{K}$.

Fig. 4

As followers of the Newtonian tradition, we clearly must demand quantitative results and proper derivations as constituting understanding.

In this regard, I would like to comment on the current calculations relating the QCD "string tension" to the short distance $\alpha_{s}$ or $\Lambda$. This connection, while conceptually important, will not constitute a quantitative triumph in the near future. The weak link is not the $\pm 30 \%$ uncertainties in the long distance physics (as discussed at this meeting, e.g., by David Gross) but the $\pm 200 \%$ in the determination of $\Lambda$ from short distance physics. (It is the theoretical rather than experimental uncertainties that are so large.) For a quantitative test, we will need the calculation of dimensionless ratios within the strong coupling regime.

The frustration of knowing the QCD Lagrangian and being unable to compute any properties of hadrons is enormous. The situation is not analogous to the earlier eras of atomic, molecular or nuclear physics. There, simple systems and properties were understood from first principles and confirmed the validity of our pictures. Many-body aspects served as a plausible source of difficulty from complication, but, even there, the underlying dynamics can often be useful. But quark binding is not even qualitatively understood.
TRAITÉ DE LA LUMIERE.

rencontrent tous deux au paffage en mefme temps, auquel cas le plus grand \& le plus fort brifera l'autre ; $\&$ quau contraire l'écume, les feüilles d'arbres \& les plumes, les fêtus \& autres tels corps fort legers, qui

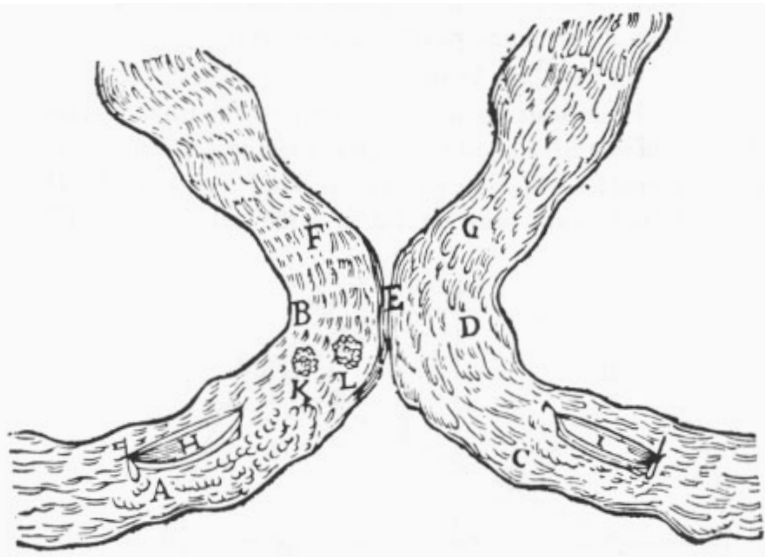

5 peuvent floter vers A, doivent eftre pouffez par le cours de l'eau qui les contient, non pas vers $E \&$ vers $G$, mais vers $B$, ou il faut penfer que l'eau eft moins forte $\&$ moins rapide que vers $E$, puifqu'elle y prend fon cours fuivant vne ligne qui eft moins approchante de 10 la droite.

Et deplus, il faut confiderer que non feulement|ces corps legers, mais auffi que d'autres, plus pefans \& plus maffifs, fe peuvent joindre en fe rencontrant, \& que, tournoyant alors avec l'eau qui les entraîne,

6 vers (second) omis. -7 que omis. -13 plus id. - en fe l'eaul qu'elle. - i non feule- renrontrant fe peuvent joindre. ment tant. - 12 mais auff - 14 que omis. - alors id.

Fig. 5

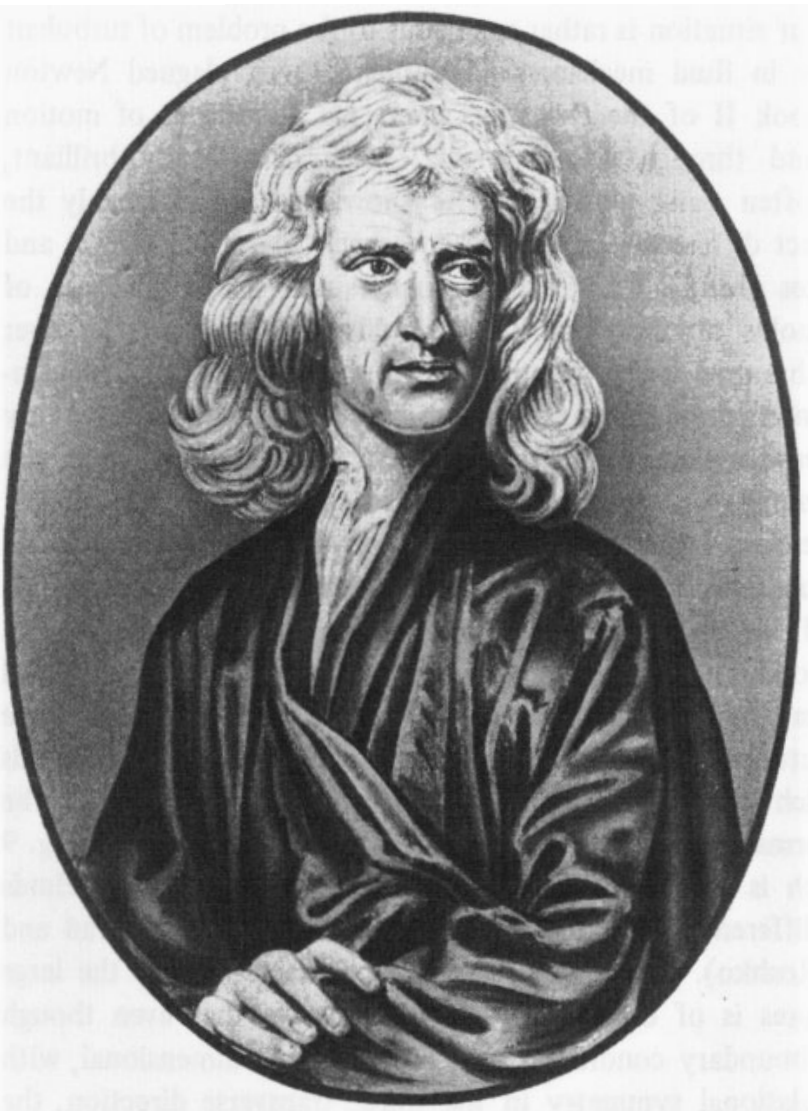

S I R I S A A C N E W T O N

Fig. 6 
NEWTON'S MATHEMATICAL PRINCIPLES

\section{SECTION III}

The motion of bodies in eccentric conic sections.

PROPOSITION XI. PROBLEM VI

If a body revolves in an ellipse; it is required to find the law of the centripetal force tending to the focus of the ellipse.

Let $S$ be the focus of the ellipse. Draw SP cutting the diameter DK of the ellipse in $\mathrm{E}$, and the ordinate $\mathrm{Q} v$ in $x$; and complete the parallelogram $\mathrm{Q} x \mathrm{PR}$. It is evident that $\mathrm{EP}$ is equal to the greater semiaxis $\mathrm{AC}$ : for drawing $\mathrm{HI}$ from the other focus $\mathrm{H}$ of the ellipse parallel to $\mathrm{EC}$, because $\mathrm{CS}, \mathrm{CH}$ are equal, ES, EI will be also equal; so that EP is the half-sum of PS, PI,

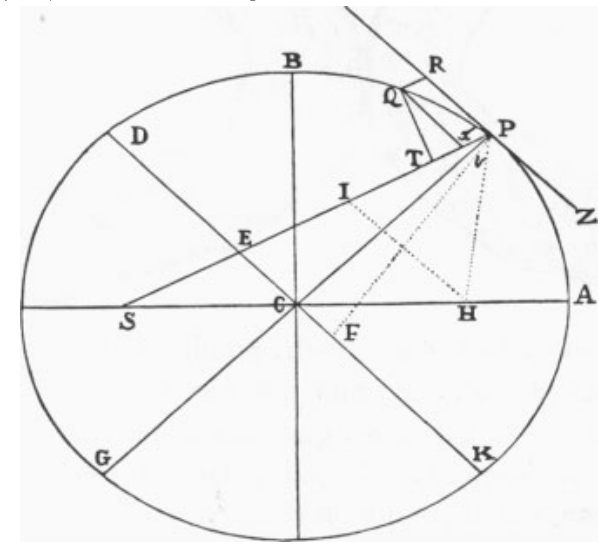

that is (because of the parallels HI, PR, and the equal angles IPR, HPZ), of PS, PH, which taken together are equal to the whole axis $2 \mathrm{AC}$. Draw QT perpendicular to $S P$, and putting $L$ for the principal latus rectum of the ellipse (or for $\frac{2 \mathrm{BC}^{2}}{\mathrm{AC}}$ ), we shall have

$\mathrm{L} \cdot \mathrm{QR}: \mathrm{L} \cdot \mathrm{P} v=\mathrm{QR}: \mathrm{P} v=\mathrm{PE}: \mathrm{PC}=\mathrm{AC}: \mathrm{PC}$,

also, $\mathrm{L} \cdot \mathrm{P} v: \mathrm{G} v \cdot \mathrm{P} v=\mathrm{L}: \mathrm{G} v$, and, $\mathrm{G} v \cdot \mathrm{P} v: \mathrm{Q}^{2}=\mathrm{PC}^{2}: \mathrm{CD}^{2}$. By Cor. II, Lem. vis, when the points $\mathrm{P}$ and $\mathrm{Q}$ coincide, $\mathrm{Q} v^{2}=\mathrm{Q} x^{2}$, and

Fig. 7

Our situation is rather analogous to the problem of turbulent flows in fluid mechanics. (Turbulence even plagued Newton in Book II of the Principia, where his discussions of motion of and through viscous media, while occasionally brilliant, are often quite muddled.) The knowledge of presumably the correct differential equations goes back to Navier (1822) and Stokes (1845), who certainly understood the significance of Reynolds number, and to Reynolds (1883). But after over one hundred years, we still lack an understanding of the phenomenon that comes from the underlying equations. Many experimentalists in the field believe that they only now are beginning to measure the relevant aspects. ... While on this digression, I thought that particle physicists would appreciate a close look at a jet. Figure 8 is a circular jet of a fluorescent fluid illuminated by laser in a thin plane (courtesy of $\mathrm{P}$. Dimotakis). The Reynolds number is of order $10^{3}$. The global zig-zag structure is a section of a helix, while the small scale structure certainly looks like one of Mandelbrot's fractals (which are, after all, just a geometric representation of the renormalization group). Another picture I really like is Fig. 9 which is a top and side view of the rolls between two fluids of different speeds and densities (courtesy of J. Konrad and A. Roshko). The Reynolds number characteristic of the large features is of order $10^{4}$. One can observe that even though the boundary conditions are essentially two dimensional, with translational symmetry in the third, transverse direction, the development of vorticity requires the third dimension, in which the flow lines can loop back on themselves.

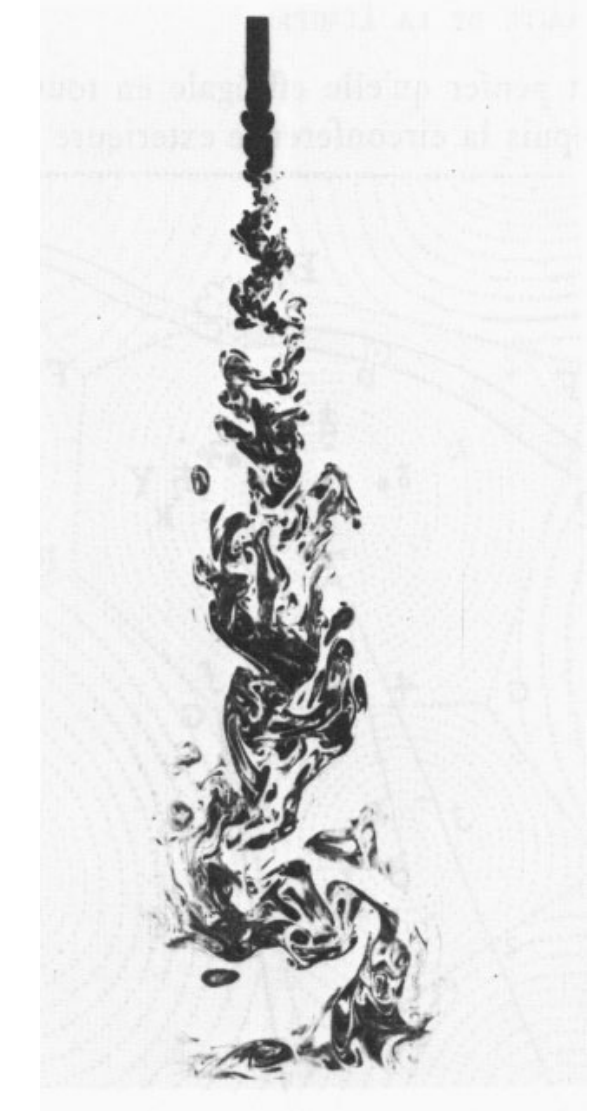

Fig. 8

A lesson I draw from this analogy is that science can (and sometimes must) move on, leaving certain essential problems unsolved. While a breakthrough in understanding turbulence would certainly constitute fundamental physics, the field is often not recognized as basic research.

This raises the question, "Is it time to move on?" Is QCD boring? If not like chemistry, is it rather like fluid mechanics? A metaphor came to my mind of the frontier of physics running forward into the future, generating swirls or vortices in its wake. From time to thime they break off. These vortices or fields continue to swirl with activity in their own right, but they fall further and further away from the fundamental frontier.

This metaphor (a poor one, at that) is primarily an excuse for one last digression, for the flow pattern I discussed is typical for Reynolds numbers of order 100 and is known as the von Kármán vortex street. [See Fig. 10.] Von Kármán headed a blueribbon panel appointed to determine why a suspension bridge built across the Takoma Narrows in the State of Washington in 1940 was totally destroyed in the first serious storm after its completion. A film of the bridge has been shown to a generation of American high school physics students as a prime example of the resonant response of a forced oscillator. Indeed, as the storm progressed, the bridge's second lowest swaying normal mode (with a node at the center) grew in amplitude until the bridge ruptured. But what in the action of the storm was forcing the bridge at the appropriate (very low $-0.2 \mathrm{~Hz}$ ) frequency? Well, the bridge was acting like a whistle, with vortices breaking off with a regular frequency, and the vortices alternate in sense of rotation.

Some of my colleagues assure me that important advances in physics occur with various frequencies, precipitating the breaking off of one field and opening a new one. They also claim that we are now due for such an advance. 


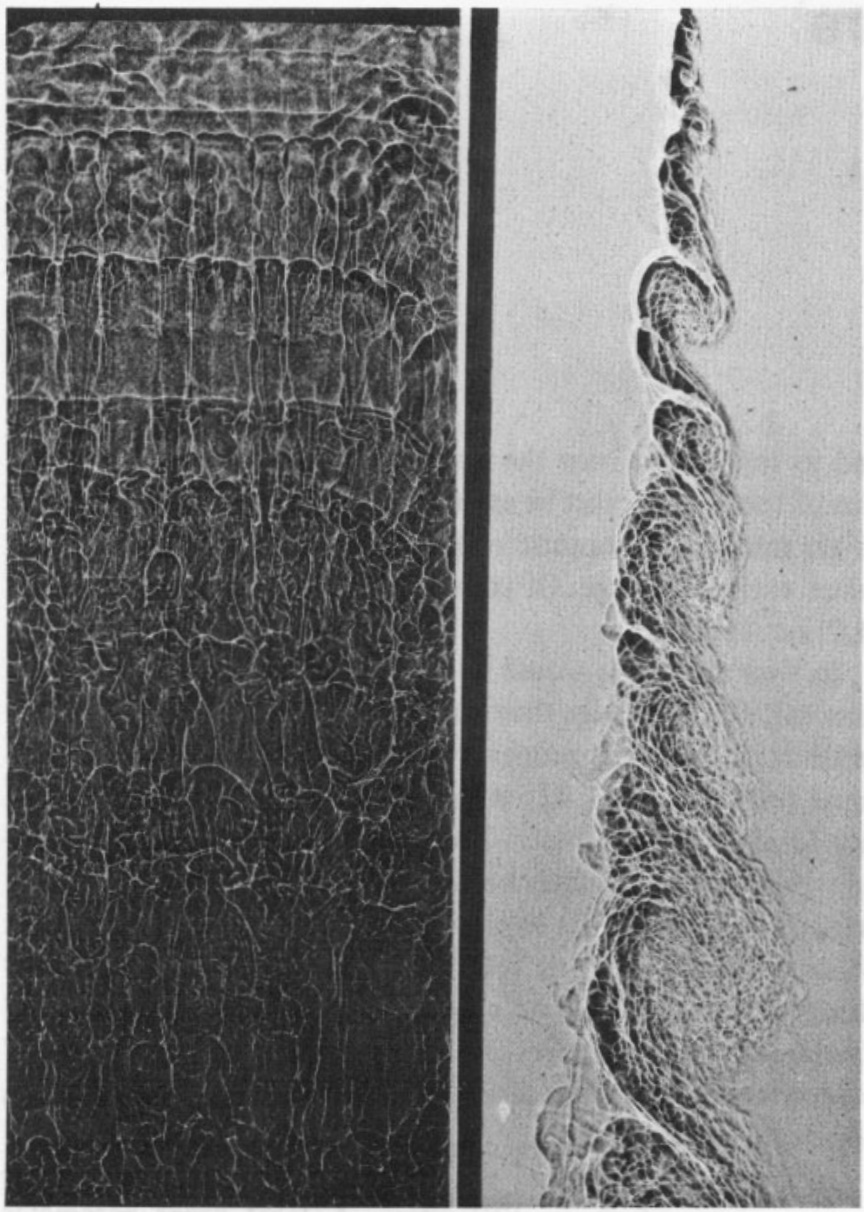

Fig. 9

But what are we to do in the meantime - besides waiting? I feel strongly that QCD research in the areas we have been pursuing is still essential to the frontier of high energy physics. Even as we wish to focus our attention on shorter and shorter distances $(\ll 1 / \Lambda)$, QCD remains important. Let me explain: From the experimental and phenomenological side, we cannot continue to afford to build bigger and bigger accelerators. If the energies reached grow only in proportion to the money spent, it won't be worth continuing if our present theoretical ideas are correct. We must devote considerable time and energy to thinking up new kinds of accelerators and/or new kinds of experiments. If one cannot do a super-high energy experiment crudely, one can often learn as much from a precise low energy experiment. Here, precision predictions (in as many different situations as possible) from QCD are an essential framework for identifying new phenomena. (At present, this path seems very difficult, but it is not impossible.) We should think of QCD tests not as attempts to confirm the basics of QCD but as searches for new phenomena. (At least, this makes the enterprise a little more exiting.)

From the theoretical side, it seems that very central issues facing Grand Unified Theories (and including supergravity) are dynamical ones. Questions of gauge hierarchies, spontaneous symmetry breaking, and the spectrum of bound states cannot be answered purely by analogy from what we know using experimental "results" of QCD because QCD is not a rich enough theory. As such, however, QCD provides probably the simplest arena for developing a theoretical understanding of gauge theory bound states. I have tried, though, to caution that with QCD we must not fool ourselves. We know so much
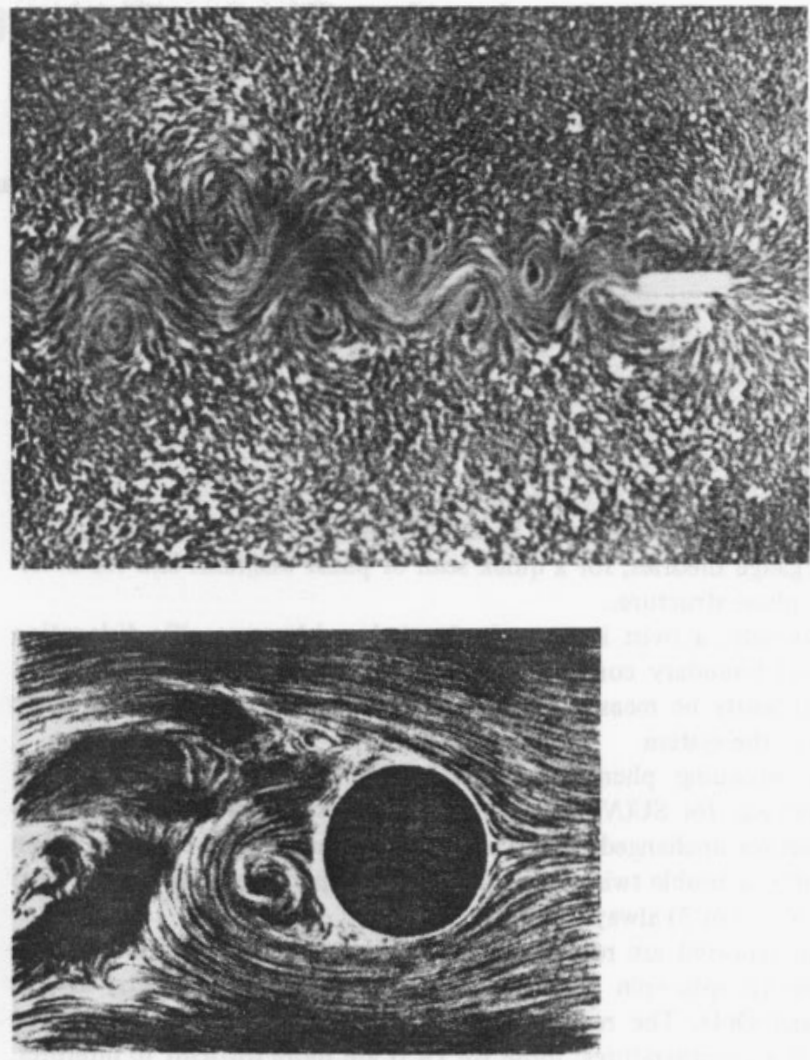

Fig. 10

from experiment that part of the answer that we are striving so hard to derive is often inadvertently assumed somewhere along in the derivation.

As I am not privy to any special or secret information, this discussion has been intended to stimulate rather than enlighten. Indeed, a good discussion followed in Copenhagen, and many of my more outrageous statements were corrected. (The original spirit appears here uncorrected, to serve again the same purpose.) A few of the comments were quite significant:

There has been real progress in the past decade in the onset of turbulence and origin of chaotic behavior. Much of it was pioneered by numerical work. So my analogy has another interesting aspect because the current numerical work on lattice gauge theories may well prove an important testing ground for theoretical ideas, before they can be developed sufficiently to face real particle experiments.

The notion of the "quick fix" (as in heroin addiction) as a recurring feature of particle physics, i.e., the succession every few years of new theoretical approaches, may have been symptomatic of an era in which we did not know where to go. Perhaps the field has now matured (grown old?). We can imagine well-defined systems, and we want to understand how they work. The era of glamorous but easy discoveries may be over. Our situation may be akin to that of many-body physics - and the growing number of fruitful exchanges is not surprising. This link may well be an important one for the future health of high energy physics.

\section{Acknowledgements}

I wish to thank the organizers and hosts of this QCD symposium. I, for one, find all aspects of QCD still enormously interesting. 